\title{
O POEMA COMO ESPAÇO DE DIALOGISMO: UM CAMINHO PARA O TRABALHO COM POESIA NA ESCOLA
} através do paralelo entre poesia e música. Como exemplo, são analisados dois poemas que retomam composições musicais, um de Mário Quintana e outro de Manuel Bandeira.

Palavras-chave: leitura de poesia, intertextualidade, poesia e música.

s estudiosos que se voltam para a análise do discurso apresentam algumas divergências de ponto de vista, mas há um aspecto sobre o qual parece haver unanimidade: trata-se da interlocução. É através do intercâmbio na comunicação que se produz o discurso, ou melhor, que se constrói o sentido.

Desde o início dos anos 80 (talvez, final dos 70), essa concepção da linguagem tem influenciado a reflexão sobre o trabalho didático com língua materna ou com língua estrangeira. Num desdobramento compreensível, os responsáveis pela capacitação docente passaram a insistir na importância do paralelo textual, enfatizando os seus resultados operacionais, tanto em termos de aprendizagem, quanto de cidadania. Esse aspecto vem sendo uma constante nos trabalhos de orientação técnica da CENP (Coordenadoria de Estudos e Normas Pedagógicas da Secretaria de Educação do Estado de São Paulo). Um roteiro exemplar é o ensaio de Adélia Bezerra de Menezes (1988) que traz um confronto entre Canções do Exilio, do Romantismo ao Modernismo.

Além da intertextualidade - o conjunto de relações explícitas ou implícitas que um texto estabelece com outros textos -, também se 
GOLDSTEIN, Norma Seltzer. 0 poema como espaço de dialogismo: um caminho para o trabalho com poesia na escola.

tem explorado o dialogismo entre as diferentes vozes de um mesmo texto, na trilha da polifonia de Bakhtin e da Semântica da Enunciação de Ducrot. O dialogismo seria inerente a todo discurso, pois, num mesmo enunciado, é possível se perceber mais de uma voz.

Ambas as propostas - a do paralelo entre textos e a do estudo dialógico no texto-, aplicadas em sala de aula, têm resultado em atividades que levam os alunos à melhora da produção textual, aperfeiçoando sua competência de leitores/redatores.

Os pesquisadores preocupados com a questão do ensino de língua materna vêm acompanhando esse tipo de atividade, buscando formas de ampliação do jogo interlocutivo em sala de aula. Surgiram daí algumas idéias sobre o diálogo entre o texto verbal e outros tipos de linguagem, como a visual e a musical.

É nesta última direção que se encaminha a presente reflexão. Ela se debruça sobre o diálogo entre dois poetas modernistas e dois músicos. Manuel Bandeira retoma um compositor erudito, enquanto Mário Quintana resgata uma cantiga folclórica.

Os dois diálogos são diversos. Enquanto Quintana retoma rítmica e tematicamente uma canção tradicional, Bandeira centra a interlocução no aspecto formal, estruturando seu poema à maneira do modo de compor de um músico erudito das primeiras décadas do século.

Comecemos pelo diálogo entabulado por Mário Quintana. Ele evoca uma cantiga de roda, bastante conhecida, até alguns anos atrás, talvez um pouco menos lembrada em nossos dias:

A CANOA VIROU

A canoa virou

Quem fez ela virar?

Foi por causa de Fulano ${ }^{1}$

Que não soube remar.

Ou Fulana, ou Beltrana etc. O nome vai sendo trocado, a cada retomada do jogo e da canção. 
A memória do leitor deverá ter registrados o brinquedo de roda, a melodia e a letra da canção que ele vai reconhecer, ao ler no poema a transformação de um enunciado que já fazia parte de sua formação discursiva. No poema, a manifestação dessa retomada aponta para um diálogo mais amplo que o textual: o paralelo entre duas épocas diferentes:

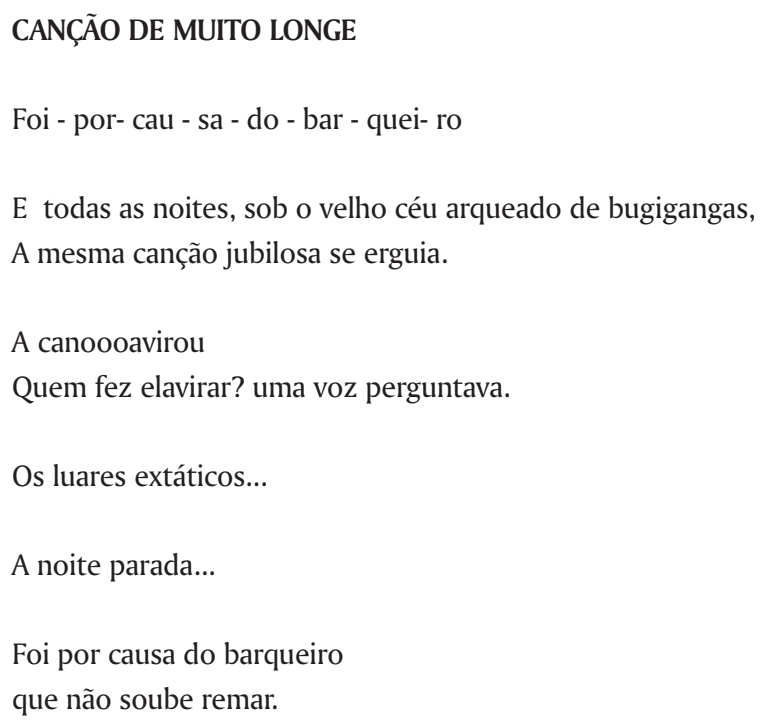

Ao se examinar o poema, percebem-se dois modos diversos de escrita: os versos 1, 4 e 5 diferem da escrita usual: no primeiro, há uma série de hífens entre as sílabas e as palavras; no quarto e na primeira parte do quinto, as palavras se juntam umas às outras. $\mathrm{O}$ leitor fica motivado a descobrir a causa disso.

O fato de essa canção estar "muito longe", como anuncia o título, refere-se não ao distanciamento no espaço, mas no tempo. $\mathrm{O}$ poema faz um apelo à memória e associa a cantiga propriamente dita - com uma escrita diferenciada - à composição poética - com escrita usual. Os dois modos de representar a escrita apontam para a superposição de vozes no poema: a do passado e a do presente; a da cantiga e a do poeta que a recria. 
GOLDSTEIN, Norma Seltzer. 0 poema como espaço de dialogismo: um caminho para o trabalho com poesia na escola.

O poema se divide em duas partes.

Na primeira, do verso 1 ao 5 , recria-se o passado. Os já mencionados versos 1, 4 e primeira metade do 5 retomam a letra da cantiga, no canto coletivo das vozes infantis, como se fossem personagens:

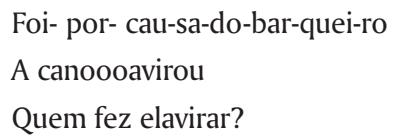

Nos versos 2, 3 e segunda metade do 5, o narrador recorda o contexto da época:

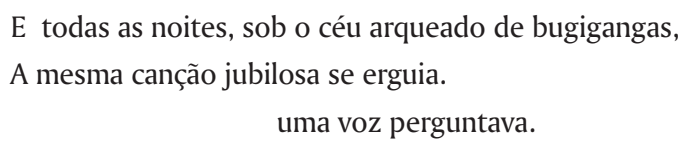

O clima era alegre, a canção é jubilosa. Ao metaforizar as estrelas, caracterizando o céu arqueado de bugigangas, sugere-se uma noite bonita, um serão de clima agradável, num tempo em que a rua era um espaço social onde as crianças brincavam de roda. $\mathrm{O}$ emprego dos verbos no pretérito imperfeito - A mesma canção se erguia e uma voz perguntava - indica a ação repetida no passado, sugerindo que a cena reflete uma constante. Ou seja, brincar de roda era um hábito, fazia parte dos costumes de certo período de nossa história.

Na primeira parte, intercalam-se as vozes das personagens e a do narrador. $O$ processo é diferente, na segunda parte, que vai do verso 6 ao 10. Apenas o narrador se manifesta, voltando-se, agora, para o tempo presente:

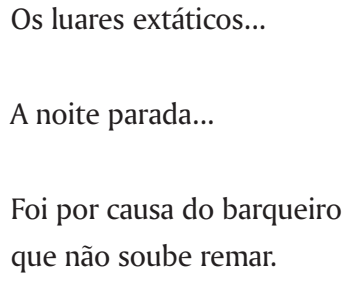


Ao descrever o contexto presente, não aparecem verbos, as frases são nominais. A construção sintática reflete a estaticidade e o vazio do cenário do qual desapareceram as personagens. Apesar do luar em êxtase, tudo está parado, sem movimento, sem vida, silencioso.

Na cantiga tradicional, um jogo de faz-de-conta achava um culpado entre os participantes do brinquedo: "Foi por causa de tal pessoa que não soube remar". Nos versos finais do poema, o causador do naufrágio é o próprio barqueiro. Pode-se pensar na sugestão de que a culpa possa ser compartilhada por todos os que não cuidaram do rumo do barco dos costumes sociais, num verdadeiro acidente que afugentou os cidadãos da rua, aprisionando-os em espaços interiores fechados.

É importante notar que, nos versos finais, embora se volte a retomar a letra da canção, a escrita é a usual, isto é, aparece um espaço entre as palavras, diferentemente dos versos da primeira parte, nos quais a canção é resgatada, com marcas gráficas criadas pelo poeta, para sugerir o canto entoado pelas vozes infantis. É através desse recurso gráfico que se marca a diferença de emissor entre a voz do poeta e os versos que retomam a canção, em cada uma das partes do texto.

Graças ao diálogo entre poesia e música, o leitor compreende o tom melancólico do poema, a partir do título: Canção de muito longe. $\mathrm{O}$ modo de vida do passado se manifesta na apropriação da letra da canção, com a escrita especial dando pistas ao leitor sobre esse espaço social diverso do de hoje. $\mathrm{O}$ folguedo do passado sugere um momento movimentado e feliz. Em contraste, a segunda parte retrata o mundo inerte e silencioso do presente, manifestando-se no texto pela forma escrita usual, em que se emprega indiretamente a letra da canção, apagando-lhe a força vital e cultural.

O diálogo estabelecido por Manuel Bandeira indica, a partir do título, sua fonte inspiradora: o compositor francês Debussy.

Debussy

Para cá, para lá...

Para cá, para lá... 
GOLDSTEIN, Norma Seltzer. 0 poema como espaço de dialogismo: um caminho para o trabalho com poesia na escola.

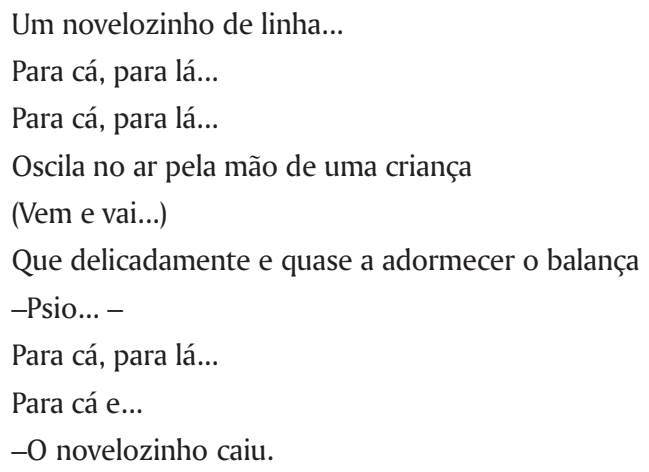

(In Carnaval, 1919)

O título do poema Debussy, de Manuel Bandeira, remete a Claude Debussy (1862-1918) compositor francês que inovou o modo de compor e influenciou a criação musical deste século, inclusive, segundo a crítica, a de nosso Heitor Villa-Lobos. $\mathrm{O}$ assunto do poema não parece ter o título como referência. Se a relação não está no tema, resta supor que o diálogo se instaura no plano formal.

Claude Debussy foi inovador. Buscou ultrapassar os cânones tradicionais e criou uma nova concepção musical, enfatizando o importante papel da sugestão. Segundo o padrão tradicional, era comum que as duas mãos tocassem o teclado do piano conjuntamente, a direita fazendo a melodia e a esquerda o acompanhamento, na metade do piano que lhes era correspondente. Debussy, bem como alguns de seus contemporâneos, inverte o papel das mãos esquerda e direita: por vezes, a esta cabe o acompanhamento, enquanto àquela se destina o fraseado melódico. Um outro recurso: a execução da peça num jogo alternado, em que as mãos deixam de tocar juntas, para atuar uma de cada vez, ampliando o alcance do teclado em relação às peças tradicionais que mantinham cada mão em sua respectiva metade do teclado. A mão esquerda passa a tocar também os agudos e a direita, a alcançar as notas mais graves.

Provavelmente, boa parte dos leitores conheça Clair de Lune, a mais divulgada peça musical de Debussy. Pediria que voltassem a ouvila. Se prestarem atenção a sua execução ao piano, perceberão tanto o 
jogo alternado das mãos sobre o teclado, quanto o desempenho melódico cedendo o papel da mão direita à esquerda, numa espécie de coreografia de braços que o pianista executa, para levar a mão esquerda às notas agudas do piano e vice-versa.

A partir do título do poema de Bandeira, o leitor tem a sugestão para as etapas da leitura do texto: a mão esquerda; a mão direita; e as duas mãos juntas. $\mathrm{O}$ modo de compor o texto remete à linguagem musical de seu inspirador. São três as leituras possíveis: 1 . Leitura do poema completo; 2. Leitura de uma mão; 3. Leitura da outra mão. A leitura do poema completo acaba de ser feita. Passo às outras duas.

\section{Primeira mão.}

Destaquemos os versos 1, 2, 4, 5, 10 e 11. Eles se assemelham, numa reiteração descritiva de um movimento pendular: Para cá, para lá...

Na última retomada, a frase se interrompe pelas reticências, retratando formal e sintaticamente o movimento inacabado ou bruscamente interrompido.

Pela sugestão do título, esse verso representaria a execução de uma das mãos. Trata-se de um verso descritivo. O que ele estaria descrevendo? Qual movimento pendular?

\section{Segunda mão}

A outra mão sugere a resposta. Seu movimento está nos seguintes versos:

3 Um novelozinho de linha

6 Oscila no ar pela mão de uma criança

$7 \quad$ (Vem e vai)

8 Que delicadamente e quase a adormecer o balança

$9 \quad-$ Psio... -

$12-\mathrm{O}$ novelozinho caiu. 
GOLDSTEIN, Norma Seltzer. 0 poema como espaço de dialogismo: um caminho para o trabalho com poesia na escola.

Nestes versos ou, se se preferir, nessa frase melódica, algumas ações se sucedem: um novelo de linha vem e vai, na mão de uma criança. Onde ela estaria sentada? Numa cadeira de balanço que se movimenta Para cá, para lá...

A cadeira leva a criança a balançar o fio de linha e a adormecer. No verso 8, é explicitado: quase a adormecer. No verso 11 , o sono se traduz pela ruptura sintática: Para cá e...

Fusão das duas mãos

No verso 12, ocorre queda do novelo que a criança adormecida acaba por soltar:

- O novelozinho caiu.

Nesse ponto, fundem-se as duas linhas melódicas num só acorde.

Cada parte do poema ou cada frase melódica poderia ser lida separadamente e faria sentido, de modo parcial. Mas é pela conjunção das duas que o leitor apreende o quadro completo: o movimento do balanço (descritivamente apresentado por uma das mãos) e a sequiência dos movimentos da criança até adormecer, deixando cair o novelo de linha (num segundo movimento, complementar ao primeiro).

O diálogo com o modo de compor de Debussy se estende para outros aspectos. Um deles é o ritmo: nos versos reiterativos da descrição, mantém-se regularidade rítmica, na mesma cadência do balanço que a indicação pendular sugere:

$\begin{array}{ccccccc}\text { Pa - ra - cá - pa - ra - lá } & \text { E. R. 6 (3-6) } \\ 1 & 2 & 3 & 4 & 5 & 6 & \text { (fraca, fraca, forte; fraca, fraca, forte). }\end{array}$

Nos versos da narração, o ritmo é irregular:

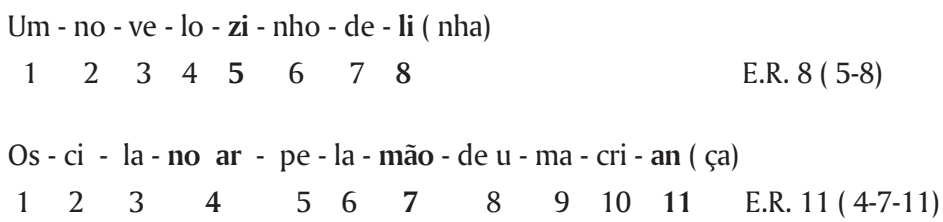




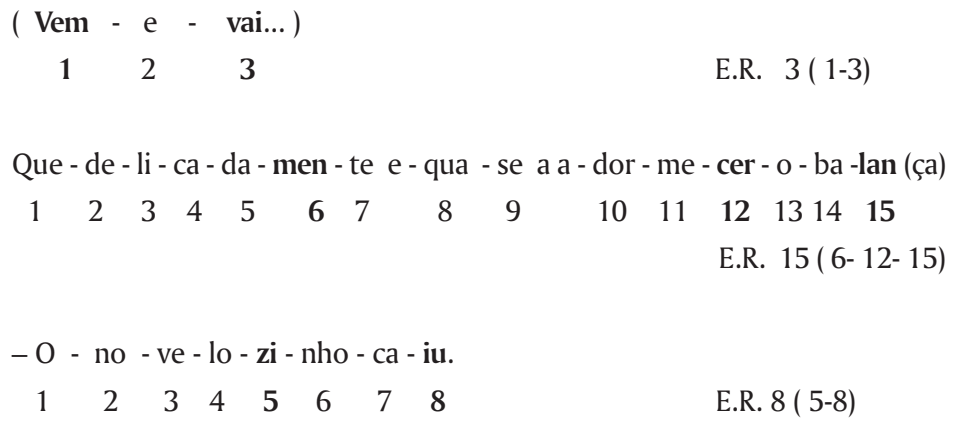

Os versos se compõem, respectivamente, de $8,11,3,15$ e 8 sílabas. $O$ primeiro e o último têm ritmo similar: oito sílabas poéticas, com acento na $5^{\mathrm{a}}$ e na $8^{\mathrm{a}}$. Os demais apresentam variação, sugerindo inovação rítmica, como a música que inspira o poema. É preciso lembrar a data da composição: 1919. Nesse momento, a polimetria dos versos revestia-se de um caráter renovador.

$\mathrm{O}$ aspecto rítmico formal do poema é o principal ponto de interlocução entre o poema e a obra musical. No entanto, seria possível estabelecer outros elos entre linguagem verbal e musical, decorrentes das características da escola impressionista: a valorização do pormenor, do detalhe; a importância das sensações, sobretudo da percepção visual; o desejo de captar o momento observado; um tom de leve delicadeza.

Esses outros aspectos também se fazem presentes no texto, projetando sobre ele os traços do estilo impressionista. O poema retrata uma cena, captada num breve espaço de tempo. O ritmo apresenta variação, pelo efeito de dois diferentes blocos de versos, alternando cadência regular e irregular. À sugestão musical, acrescentam-se a percepção visual e a sonora. Os aspectos formais do texto sugerem o movimento pendular da criança sobre a cadeira de balanço, captado num instantâneo marcado pela espontaneidade e delicadeza.

O poema Debussy se encontra em Carnaval, obra datada de 1919, um ano após a morte do compositor. É possível supor que o poeta proponha um diálogo entre a forma de compor o poema e o processo musical de composição do artista francês. Trata-se de uma pista que o 
GOLDSTEIN, Norma Seltzer. 0 poema como espaço de dialogismo: um caminho para o trabalho com poesia na escola.

leitor deve seguir: por um lado, os ecos musicais ampliam e aprofundam os feixes de significação do poema; por outro, essa proposta talvez possa levá-lo a seguir em busca de novos diálogos.

\section{BIBLIOGRAFIA}

BANDEIRA, M. (1966) Estrela da vida inteira. Rio de Janeiro, José Olympio.

MENEZES, A. B. de. (1988) As canções do exílio: estudo comparativo. In Subsídios à proposta curricular de língua portuguesa, v. 3. São Paulo, CENP S.E.E.S.P., p. 95-116.

Proposta curricular para o ensino de língua portuguesa no primeiro grau (1991) São Paulo, CENP S.E.E.S.P.

QUINTANA, M. (1987) Nova antologia poética. Rio de Janeiro, Globo.

ABSTRACT: This article presents an intertextual proposal: reading poetry in school, through a paralel between poem and music. Two poems whose structure and meaning are based upon musical compositions are taken as examples, one by Mário Quintana and the other by Manuel Bandeira.

Keywords: reading poetry, poetry and music, intertextuality. 